\title{
Recent Studies and Developments in Titanium Biomaterials
}

\author{
M. Ikeda ${ }^{\text {a, }}{ }^{*}$, M. Ueda ${ }^{\text {a }}$ and M. Ninomi ${ }^{\text {b }}$

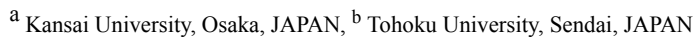 \\ *hikoik@kansai-u.ac.jp
}

\section{Abstract}

Titanium and its alloys have a high specific strength, excellent corrosion resistance, and good biocompatibility. Therefore, these alloys are adopted as raw materials for artificial bones and joints. Furthermore, these alloys are used as materials for dental surgery. In the development of alloy design, beta-type titanium alloys that possess a lower Young's modulus than other types of titanium alloys, e.g., Ti-6Al-4V alpha-beta-type alloys, are being actively investigated worldwide. Based on these studies, titanium-niobium-tantalum and zirconium system alloys were developed. For example, Ti-29Nb-13Ta-4.6Zr alloy has a low Young's modulus, excellent biocompatibility, and improved mechanical properties. Many researchers are actively investigating surface modifications and surface treatments. Additive manufacturing, namely $3 \mathrm{D}$ printing, wherein metal powders are piled up layer by layer to produce goods without a mold, has attracted attention in many fields, including manufacture of implants, especially porous structural implants with a low Young's modulus. It is very important that titanium and its alloys be applied to health-care goods, e.g., wheelchairs and prostheses. Therefore, we herein consider four topics: alloy development, coating and surface modification, additive manufacturing, and health care applications.

\section{Introduction}

Metallic biomaterial, namely, gold, has been applied to dental treatment of the human body since around 700 BCE [1]. Around 400 BCE, in Greece, gold wires were used in the treatment of broken bones [1]. After that, amalgam, tin, bronze, and iron alloys were applied to the treatment of the human body [1]. Stainless steels and Co-Cr alloys began to be used in the treatment of the human body from around 1930 in the US [1].

Titanium and its alloys have high specific strength (ratio of tensile strength to density), excellent corrosion resistance, and good biocompatibility [2]. Titanium and its alloys that have these excellent properties have been applied in numerous applications, i.e., from airplanes to golf clubs [2]. One reason for the good biocompatibility of titanium is its excellent corrosion resistance. In general, biomaterials are used in contact with human tissue. Therefore, it is imperative that contact does not have harmful effects on human tissue. A significant cause of such harmful effects is considered to be eluted metallic ions. Thus, such a situation is avoided by the suppression of eluted metallic ions.

Titanium began to be applied to dental treatment in humans in 1965 after Per-Ingvar Brånemark of University of Gothenburg discovered osseointegration between bone and titanium [3]. Around 1960 in Sweden, artificial joints were made from titanium.

In the proceedings of the $5^{\text {th }}$ International Conference on Titanium, Munich, 1984 (session on medical applications)[4] and the $6^{\text {th }}$ World Conference on Titanium, Cannes, 1988 [5] (Plenary Papers in CIS languages and German), medical and dental applications of titanium and its alloys were presented. (The name of the conference at Cannes was changed to the World Conference on Titanium.) Since these conferences, sessions on titanium and its alloys concerning biomaterials have likely been held continuously. Therefore, medical applications are significant in the fields of titanium and its alloys.

In the present paper, we consider alloy development, coating and surface modification, additive manufacturing (AM), and health care applications.

\section{Alloy developments in titanium biomaterials}

Commercial pure titanium has relatively high strength, high specific strength, and excellent corrosion resistance, especially against sea water [2]. Moreover, titanium has excellent corrosion resistance against body fluids. Commercial pure titanium was initially used in biomedical applications as metallic biomaterials. Although commercial pure titanium has excellent corrosion resistance, titanium alloys must be used in these applications because of the low strength of commercial pure titanium. Initially, although new titanium alloys were not developed for metallic biomaterials, Ti-6Al-4V alpha-beta-type alloy, which was developed for aerospace applications, was used in medical applications [6]. Unfortunately, Ti-6Al-4V alpha-beta-type alloy contains vanadium, which is a toxic metallic element, and aluminum, which was suspected as a cause of Alzheimer's disease.

In order to avoid toxic metals, e.g., vanadium, Ti-6Al-7 Nb alloy was developed in 1977 as an alpha-beta titanium alloy with the substitution of $\mathrm{Nb}$ for $\mathrm{V}$ [7]. Table 1 shows physical, e.g. Young's modulus and mechanical properties, e.g. Tensile strength. Young's modulus of Ti-6Al-7Nb alloy is approximately the same as that of Ti-6Al-4V alloy [7].

\begin{tabular}{|c|c|c|c|}
\hline beta transus & $1010 \pm 10^{\circ} \mathrm{C}$ & $\begin{array}{l}0.2 \% \\
\text { proof stress }\end{array}$ & 800 to $900 \mathrm{MPa}$ \\
\hline $\begin{array}{l}\text { melting } \\
\text { (liquid) point }\end{array}$ & Not Available & $\begin{array}{l}\text { tensile } \\
\text { strength }\end{array}$ & 900 to $1000 \mathrm{MPa}$ \\
\hline Density & $4.52 \mathrm{~g} / \mathrm{cm}^{3}$ & $\begin{array}{l}\text { Elongation } \\
\text { on 5D }\end{array}$ & 10 to $20 \%$ \\
\hline Elastic modulus & $105 \mathrm{GPa}$ & $\begin{array}{l}\text { Reduction } \\
\text { of area }\end{array}$ & 25 to $35 \%$ \\
\hline $\begin{array}{l}\text { Electrical } \\
\text { resisitivity }\end{array}$ & Not Available & Fatigue & $\begin{array}{l} \pm 500 \mathrm{MPa} \\
\text { at } 10^{7} \text { cycles }\end{array}$ \\
\hline $\begin{array}{l}\text { Magnetic } \\
\text { permeability }\end{array}$ & Nommagnetic & & \\
\hline
\end{tabular}

Although Ti-6Al-7Nb has better biocompatibility than Ti-6Al-4V, Young's moduli of these alpha-beta-type titanium alloys, approximately $100 \mathrm{GPa}$, are higher than that of human bone (cortical bone), 10 to $30 \mathrm{GPa}$. One Ti-Zr alloy used for biomaterial, Ti-15Zr-4Nb-4Ta-0.2Pd, was developed in Japan. This alloy consists of non-toxic, although expensive, metallic elements. Moreover, Ti-6Al-7Nb and Ti-15Zr-4Nb-4Ta-0.2Pd alloys have a slightly higher fatigue strength than Ti-6Al-7Nb (Figure 1) [8,9].

(C) The Authors, published by EDP Sciences. This is an open access article distributed under the terms of the Creative Commons Attribution License 4.0 (http://creativecommons.org/licenses/by/4.0/). 


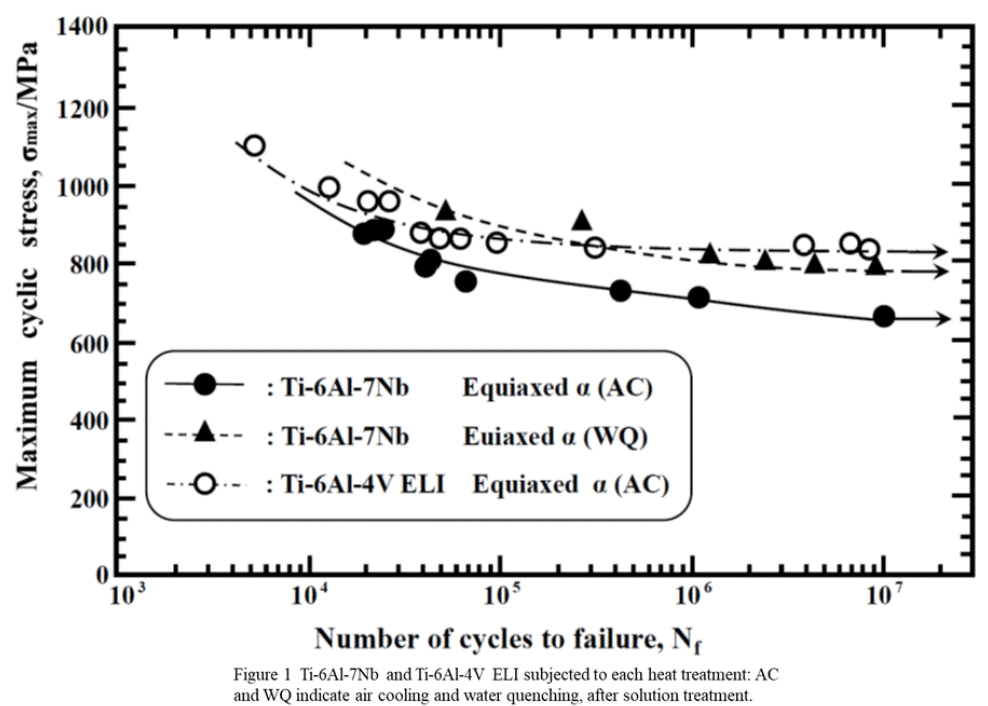

order to improve the fatigue strength of these alloys, the alloys were heat treated, e.g., Ti-6Al-4V alloy was aged at $833 \mathrm{~K}$ for 4 hours after being solution treated at $1,243 \mathrm{~K}$ for 1 hour or being air cooled. Furthermore, by thermochemical processing by hydrogenation and dehydrogenation, the fatigue strength of Ti-6Al-4V alloy was improved by improving the fine microstructure. By these processes, the fatigue strength of alpha-beta-type titanium alloys, e.g., Ti-6Al-4V alloy, could be improved.

However, the Young's moduli of these alloys are higher than that of bone, approximately $20 \mathrm{GPa}$. Moreover, these values increase by aging treatment because of alpha precipitates. Stress shielding occurs by the large difference in Young's modulus between biomaterial and bone. Bone resorption (stress shielding) occurs because of the difference in elastic deformation between bone and biomaterial upon remodeling. The difference in elastic deformation is due to the difference in Young's moduli between bone and biomaterial. The difference is calculated simply using the strength of materials method. In general, the Young's moduli of beta titanium alloys are lower than those of alpha and alpha-beta-type titanium alloys (Figure 2) [10, 11].

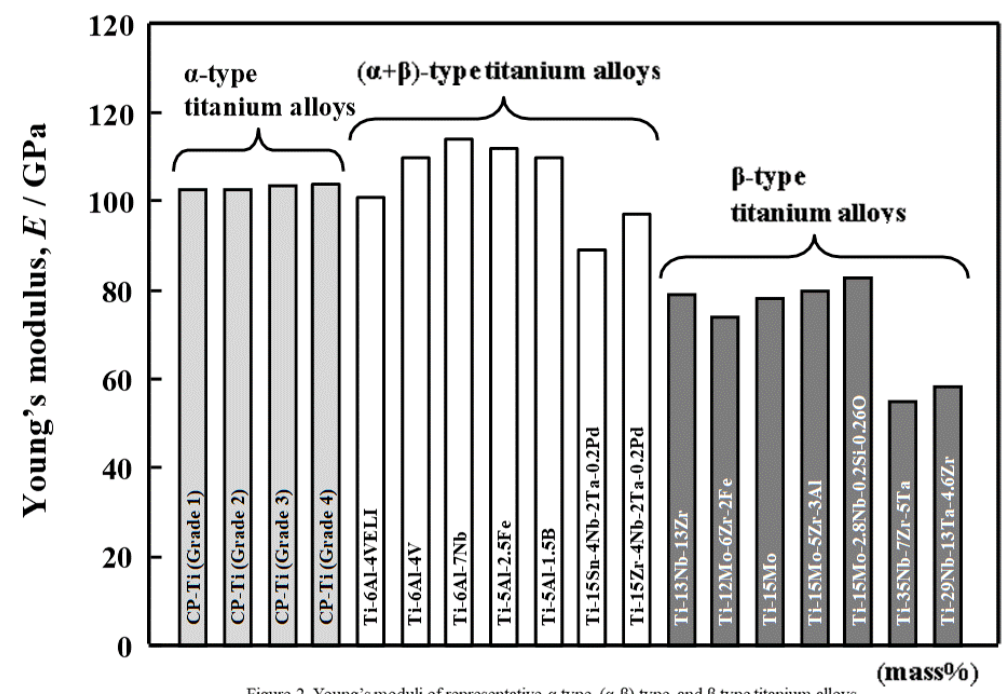

However, the Young's modulus of a beta-type titanium alloy, approximately $80 \mathrm{MPa}$, is much higher than that of bone, approximately $20 \mathrm{GPa}$. Therefore, many beta-type titanium alloys possessing low Young's moduli were developed. For example, beta titanium alloys include Ti-13Nb-13Zr (near-beta-type, ASTM F 1713), Ti-12Mo-6Zr-2Fe (ASTM F 1813), Ti-15Mo (ASTM 2006), Ti-16Nb-10Hf (Tiadyne 1610), Ti-15Mo-5Zr-3Al (JIS T 7401-6), Ti-45Nb (AMS 4982), Ti-35Nb-7Zr-5Ta (TNZT Task Force F-04.12.23), Ti-29Nb-13Ta-4.6Zr (TNTZ), Ti23Nb-0.7Ta-2.0Zr-1.2O (gum metal), Ti-28Nb-13Zr-0.5Fe (TNZF), Ti-24Nb-4Zr-7.9Sn (Ti2448), Ti-12Mo-3Nb, and Ti-12Cr alloys, which have a low Young's modulus [12]. Although most alloys consist of nontoxic metallic elements, i.e., $\mathrm{Nb}$, Ta, and $\mathrm{Zr}$, some alloys consist of Mo and $\mathrm{Cr}$, which are probably not toxic. Among Ti-Nb-Ta-Zr alloys, Ti-29Nb-13Ta-4.6Zr, which is a commonly used alloy, has a lower Young's modulus, i.e., approximately $60 \mathrm{MPa}$, as bulk. In metastable beta-type titanium alloy single crystals, e.g., Ti-29Nb-13Ta-4.6Zr alloy and Ti-15Mo-5Zr-3Al alloy, Young's modulus varies with lattice direction, and the lowest value is obtained for the $<100>$ direction (Figure 3) [13]. 


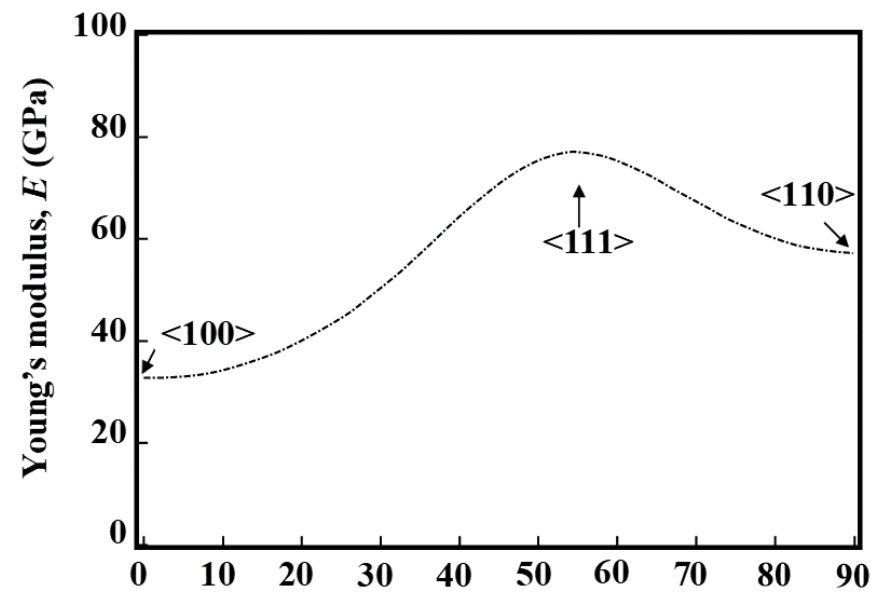

Angle, $\theta$ (degree) Figure 3 Young's modulus of single-crystal Ti-29Nb-13Ta-4.6Zr alloy
in directions between [100] and [110].

Bone resorption occurs due to stress-shielding delay as a result of the low Young's modulus of titanium alloy upon remodeling. For example, this influence was reported in a study on bone remodeling using Fe-17Cr-12Ni with low carbon (SUS 316L), Ti-6Al-4V, and Ti-29Nb-13Ta-4.6Zr (TNTZ) [14].

Shape-memory and superelastic alloys are very useful for medical applications. For example, NiTi has been applied to the guide wire of catheters and orthodontic wires, e.g., teethstraightening wires [15]. However, although NiTi has excellent shape-memory and superelasticity characteristics, NiTi tends to be avoided by medical doctors and dentists due to the toxicity of nickel. Therefore, new shape-memory and superplasticity titanium alloys are being developed without the addition of nickel. Nickel-free shape-memory and superelastic alloys are classified into three groups, i.e., Ti-Nb-system, Ti-Mo-system, and Ti-Ta-system alloys. Moreover, Ti-Cr shape-memory and superelastic alloys are also being actively developed. Table 2 shows some of the alloys in these four alloy groups [16].

A low Young's modulus is very important to suppress stress shielding, as mentioned above. Alloys with a low Young's modulus possess high spring-back, and devices made from betatype titanium alloys have a low Young's modulus. It is difficult to adjust alloys that have a low Young's modulus to a demanded shape by plastic deformation. Therefore, medical devices constructed of titanium alloys cannot be easily adjusted to the demanded shape upon surgical treatment.

If titanium alloys having a relatively higher Young's modulus are applied to a bone plate, the weight of the human body mainly loads the bone plate. To solve this problem, Young's modulus self-adjustable titanium alloys were developed. The self-adjustable function means that the Young's modulus ranges from low to high by plastic deformation because of the athermal omega formation by the deformation and the high Young's modulus of the omega structure (Figure 4) [17]. Alloys with this function include Ti-12Cr, Ti-17Mo, and Ti-11Cr-0.2O [18]

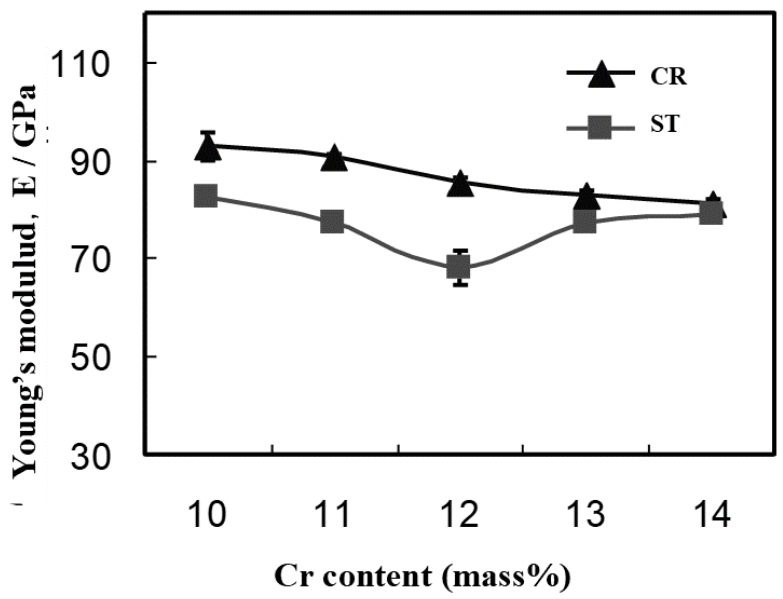

Figure 4 Young's moduli of Ti-(10-14)Cr alloys subjected to solution treatment (ST) and $10 \%$ cold rolling (CR) after ST and $Q$

\section{Coatings and surface modifications for biomaterials}

Titanium and its alloys have excellent biocompatibility among metallic biomaterials, $\mathrm{Fe}-\mathrm{Cr}$-Ni alloys, and Co-Cr-Mo alloys, because they are surface coated with titanium oxide. Although titanium alloys have excellent biocompatibility, the capacity for biocompatibility is approximately the same as bioinert ceramics, e.g., alumina and zirconia. Therefore, surface modifications of titanium alloys are needed in order to improve biofunctionalities on surfaces. In order to improve their surfaces, bioactive ceramics, such as hydroxyapatite (HAP) and phosphate calcium (CaP), or compatible blood polymers, such as polyethylene glycol (PEG), are coated on their surfaces. There are dry and wet methods of surface modifications. Dry processes include the plasma spray method, ion plating, RF magnetron sputtering, the pulse laser deposition method, the ion beam dynamic mixing method, the superplastic joining method (in which HAP is formed directly on the titanium alloy surface), calcium ion implantation, and the calcium ion mixing method (in which HAP is formed indirectly on the titanium alloy surface) $[19,20]$. Wet processes include electrochemical treatments, which are direct HAP forming methods, and alkali treatments, which are indirect HAP forming methods [19, 20].

Moreover, only the morphology of the surface is modified by surface modification in order to improve the biocompatibility of bone. As another surface modification, an antibacterial activity effect is added to titanium oxide layers having biocompatibility through the addition of silver or copper to these layers. As another approach, the demanded area of biomaterials, e.g. titanium alloys, is quickly coated with a calcium phosphate layer by the laser-assisted biomimetic process (Figure 5) [21, 22]. 


\section{Laser-assisted bjomimetic process}

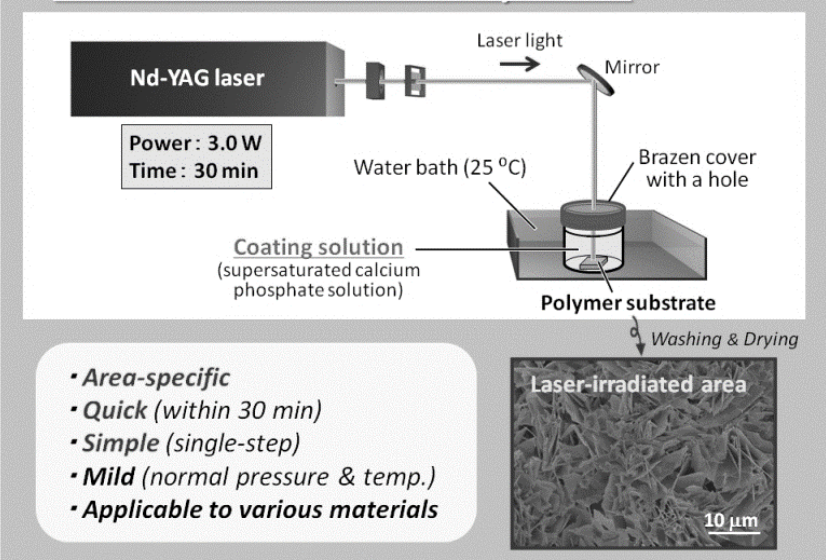

Figure 5 Explanation of leaser-assisted biomimetic proces.

mirror surface on titanium alloys is obtained by electrophoretic deposition (EDP) wheel polishing. An EPD wheel is prepared by electrophoretic deposition using silica and ceria (ceric oxide) particles as abrasive grains [23]. Several techniques have been used to attach/detach cells to/from a substrate. Cells cultured on a substrate are generally separated from the substrate into a sheet by the destruction of proteins between the cells and the substrate using enzymes such as trypsin. However, these enzymes also damage the adhesion molecules among the cells. In order to solve this problem, photo-responsive cell culture vessels using $\mathrm{TiO}_{2}$ have been fabricated and the adhesion/proliferation behaviors of cells on these vessels have been investigated (Figure 6) [24].
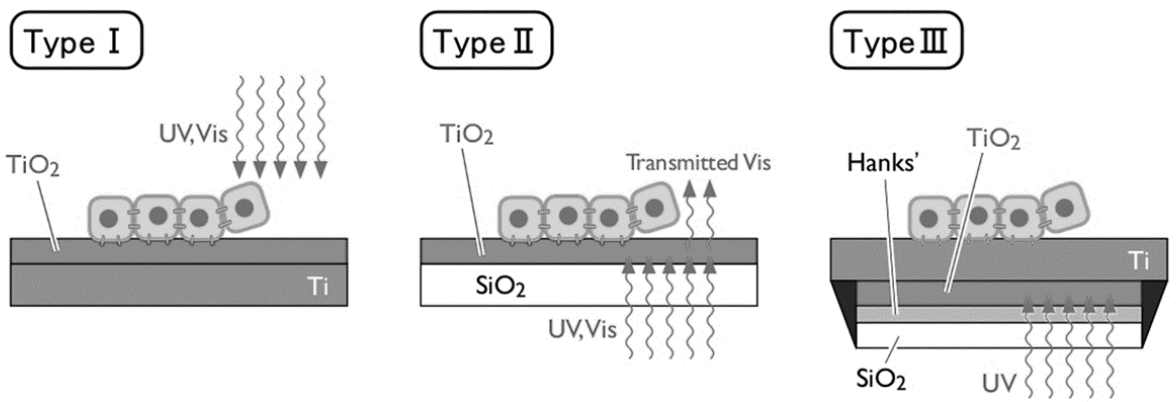

Figure 6 Explanation of Three different Types of Cell Culture Vessels.

Figure 7 shows the progress in the research and practice of surface treatment and modification for achieving bone formation function in dental implants as an example [25]. Research on surface modification has progressed to the fourth generation, and fifth generation research is desired. The practice of surface treatment has progressed to the middle of the third stage. At present, the stage selected for the coating of most metallic biomaterials is crucial.

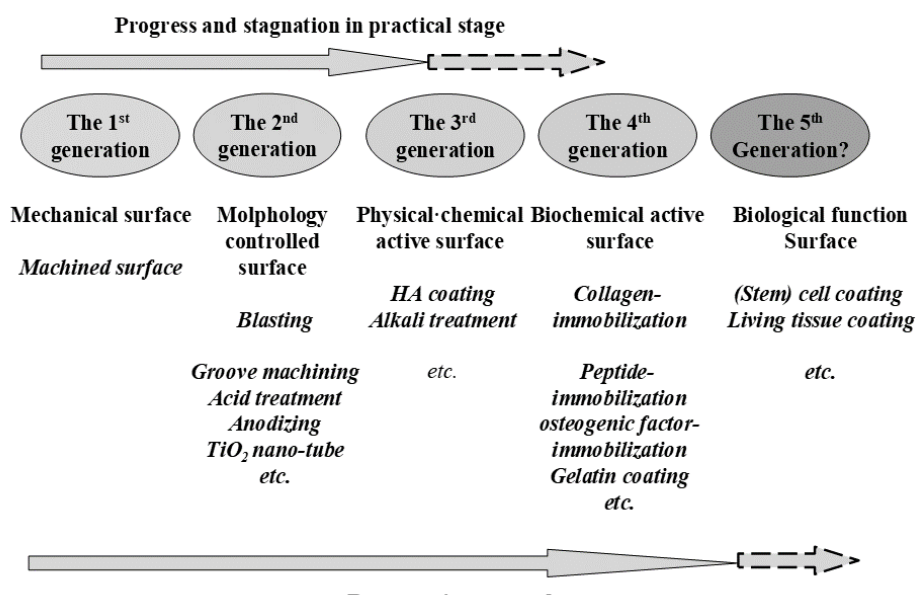

Progress in research stage

Figure 7 Progress in research and practical stage of surface treatment and modification for achieving 


\section{Additive manufacturing of titanium biomaterials}

The application for a patent on the concept of AM was made in 1980, and this technique was reported in 1981 by Hideo Kodama [26]. The study of metal AM was proceeding at pace by 1990. Direct laser sintering was developed in 1995 by EOS, Germany, and the method of electron beam melting was established in 2002 by ARCAM, Sweden [26].

In his 2013 State of the Union Address, President Barack Obama said "There are things we can do, right now, to accelerate this trend. Last year, we created our first manufacturing innovation institute in Youngstown, Ohio. A once-shuttered warehouse is now a state-of-the-art lab where new workers are mastering the 3D printing that has the potential to revolutionize the way we make almost everything. There's no reason this can't happen in other towns. So tonight, I'm announcing the launch of three more of these manufacturing hubs, where businesses will partner with the Departments of Defense and Energy to turn regions left behind by globalization into global centers of high-tech jobs. And I ask this Congress to help create a network of fifteen of these hubs and guarantee that the next revolution in manufacturing is Made in America" [27]. Based on this speech, 3D printing, i.e., AM, was actively investigated and developed throughout the world.

Although titanium and its alloys have a high specific strength, excellent corrosion resistance, and good biocompatibility, these materials possess active reactivity against some gases, especially oxygen. Moreover, these materials are not quite suitable for machining. Therefore, for titanium and its alloys, AM is an excellent manufacturing process. Advances in AM include lower contamination of goods due to a no-mold process, net shape processing without machining, reduced contamination by gases (mainly oxygen associated with the vacuum process), and custom processing.

It is very important that medical structural devices, e.g., bone plates, have a low Young's modulus for suppression of bone resorption, i.e., stress shielding. However, there is a limit to the Young's modulus of titanium bulk. Therefore, in order to lower the Young's modulus, it is necessary to change the shape and structure, e.g., the porous structure, of titanium. Young's modulus of titanium is easily controlled by making a porous body by the AM process (Figure 8) [28]

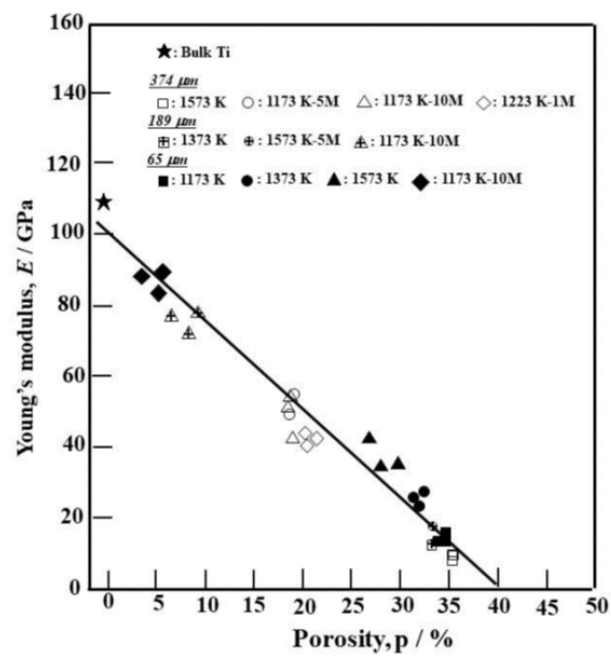

Figure 8 Young's modulus of porous Ti as a function of porosity

Porous components are also formed using Ti-6Al-4V alloy as a raw material by the AM method, and the Young's modulus of these porous components is easily changed by changing the porosity of the components.

Su-Hua Wu et al. [29] evaluated the efficiency of a Ti-6V-4Al porous cage in promoting spinal fusion and osseointegration compared to the traditional poly-ether-ether-ketone (PEEK) cage in a preclinical sheep cervical intervertebral fusion model. As a result, they reported that the implantation of porous Ti-6V-4Al cages fabricated by AM could achieve rapid bone ingrowth and that better bone-material integration and mechanical stability was obtained, as compared to PEEK cages. Porous titanium-alloy devices constructed by the AM process were shown to be very useful for medical applications.

Furthermore, the parameters of microstructures, the microstructure, and the crystallographic texture, can also be controlled by AM. In low-Young's-modulus titanium alloys, it is possible to control the crystallographic direction to that of the lowest Young's modulus by AM.

Additive manufacturing processes have higher potential to improve the suitable shape, suitable microstructure, and good mechanical properties.

\section{Titanium alloys in healthcare applications [30]}

Titanium and its alloys also are used in the manufacture of health-care goods. Commercial pure titanium is used to manufacture daily-use goods for disabled people, e.g., spoons and forks (as shown in Figure 9) [31]. Both men and women can easily modify the shapes of these goods, but these goods do not bend with regular use. 

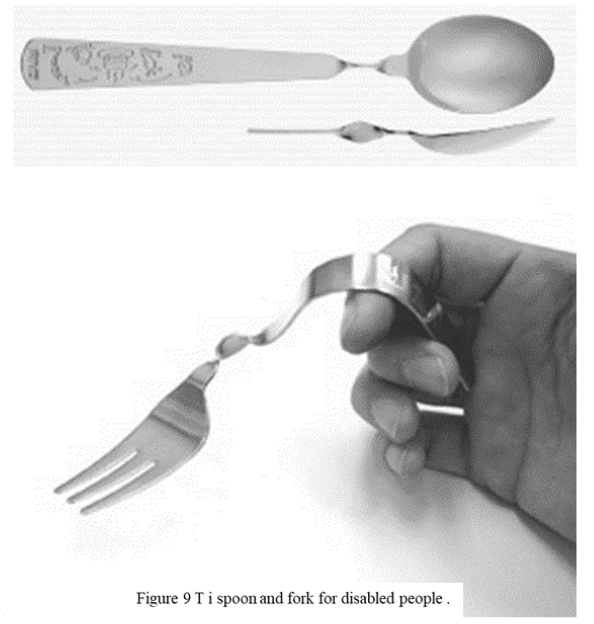

Wheelchairs for adults (Figure 10) and children (Figures 11) are constructed of titanium and its alloys [32].

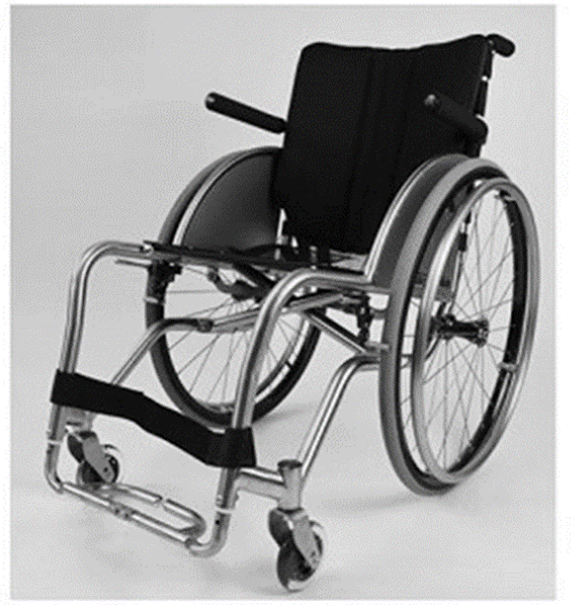

Figure 10 Ti wheel chair for adults.

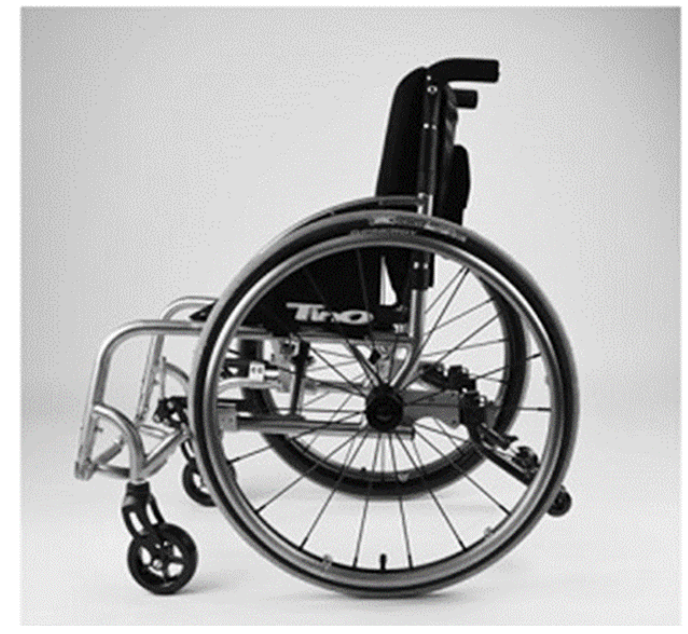

Figure $11 \mathrm{Ti}$ wheel chair for children.

Such wheelchairs are more expensive that those made from aluminum alloys. Wheelchairs for sports, e.g., basketball (Figure 12) [32], tennis, and badminton, are also made from titanium and its alloys because such wheelchairs are lightweight and have excellent drivability and toughness. Of course, wheelchairs constructed of aluminum and its alloys are also used in sports. 


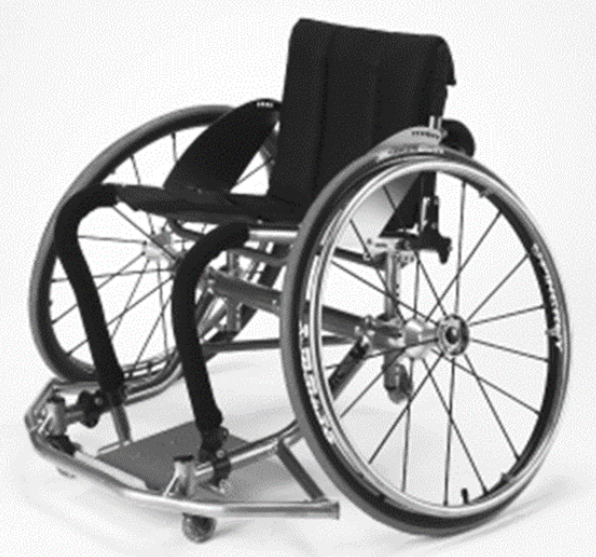

Figure 12 Ti wheel chair for sport, basketball.

Prostheses components are also made from titanium and its alloys, mainly commercial pure titanium because it has low weight, high specific strength, excellent corrosion resistance, and good biocompatibility. For example, prostheses often have socket adaptors (Figure 13) and manual-lock knee joints (Figure 14) [33].

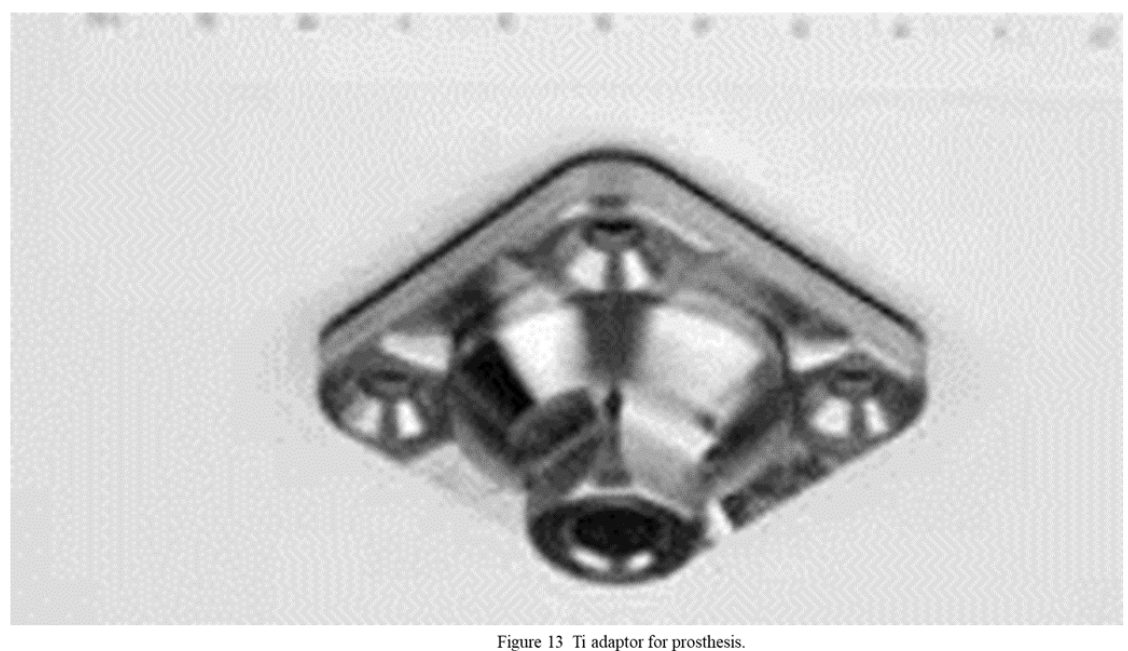

Figure 13 Ti adaptor for prosthesis.

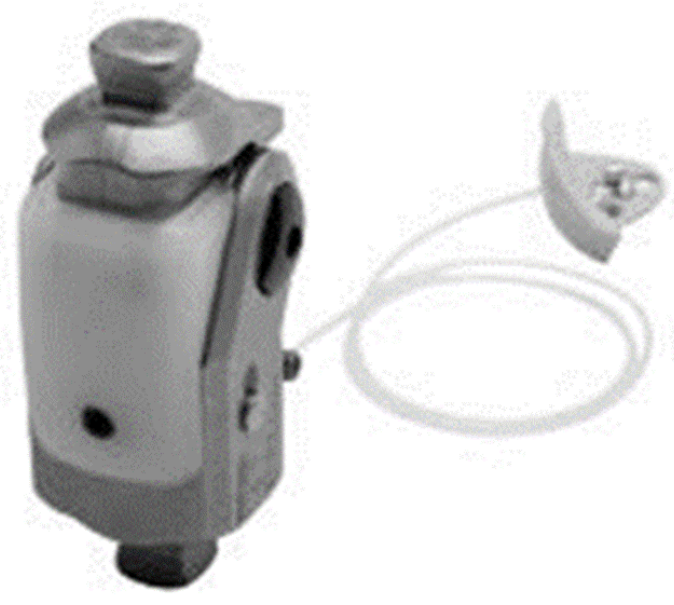

Figure 14 Ti manual lock knee joint for prosthesis.

These components are also produced from stainless steel and aluminum alloys. Unfortunately, the health-care application area of titanium and its alloys has not expanded, most likely due to expense. In a society in which elderly persons can work, goods that support the elderly are needed. Therefore, it is expected that the use of titanium and its alloys in such goods will expand. 
Titanium and its alloys are very useful as metallic biomaterials. Development of titanium alloys as metallic biomaterials was successful, and we obtained titanium system biomaterials that possess a wide range of excellent properties, e.g., good biocompatibility, excellent corrosion resistance, and a low Young's modulus. At present, low-cost titanium system biomaterials are being developed, although it is not clear which developments will be useful for medical applications. Surface modifications of titanium and its alloys have been developed in wet and dry processes. Moreover, the processes of these modifications range from traditional and straightforward methods to sophisticated and innovative methods. Additive manufacturing is a beneficial method for biomedical components constructed of titanium alloys, e.g., a custom process, because it is necessary to reduce the burden on the patient. Finally, applications of titanium and its alloys to health-care goods has progressed slowly, because such materials are costly and because of poor communication between developers and investigators of titanium alloys and healthcare product manufacturers. We expect that the use of titanium and its alloys will expand in biomedical application fields with the development of new alloys and manufacturing techniques.

\section{References}

[1] J. Tanaka, M. Sumie and T. Tateichi, Biomaterials, UHCHIDA ROKAKUHO PUBLISHBING CO., LTD, Tokyo, (2008) 33-36 (Japanese).

[2] G. Luetjering and J. C. Williams, Titanium, Springer-Verlag, Berlin, (2003) 13-51.

[3] Home page of Associated Branemark Osseointegration Centers, URL: http://branemark.se/

[4] Proceedings of International Conference on Titanium, Eds. by G. Luetjering, U. Zwickers and W. Bunk, DGM, (1985) 1327-1402.

[5] Proceedings of World Conference on Titanium, Fds. by P. Lacombe, R, Tricot and G. Beranger, Les Editions de Physique, (1989), 1-70.

[6] G. Luetjering and J. C. Williams, Titanium, Springer-Verlag, Berlin, (2003) 345.

[7] Materials Properties Handbook Titanium Alloys, Eds. by R. Boyer, G. Welsch and E. W. Collings, ASM, Materials Park, (1994) 693.

[8] R. Zwicker K. Buehler, H. Beck H and H. J. Schmid: In: Titanium'80,TMS-AIME, Warrendale, (1980) 505-514.

[9] T. Akahori, M. Niinomi, K. Fukunaga and I. Inagaki:Met. Mat. Transaction A, 31(2000), 1949-1958.

[10] M. Nakai, M. Niinomi, K. Cho and K. Narita: In: Interface Oral Health Science 2014, Springer, (2015) 79-91.

[11] M. Niinomi, M, Nakai and J, Hieda: ActaBiomaterialia, 8(2012), 3888-3903.

[12] M. Niinomi, T. Hattori, T. Kasuga and H. Fukui: Titanium and its alloys, Encyclopedia of Biomaterials and Biomedical Engineering, Marcel Dekker, INC, (2006), 1-8.

[13] A. Chiba, K. Kumagai, H. Takeda and N. Nomura: Mater. Sci. Forum, 475-479(2005) 2317-2322.

[14] Private communication of Prof. Hattori.

[15] Metal for Medicine, Ed. by T, Hanawa, JIM, Sndai, (2010) 30-40.

[16] M. Niinomi: In: Biomaterials for Spinal Surgery, Woodhead Publishing Ltd., (2012), 462-490.

[17] X.F. Zhao, M. Niinomi, M. Nakai, J. Hieda: Acta Biomater., 8(2012), 2392-2400.

[18] M. Niinomi, T. Hattori and M. Nakai: J. Jpn. Soc. Bone Morphometry, 23(2014) 23-30.

[19] M. Niinomi: STAM, 4(2003), 445-454

[20] T. Hanawa: Materia Japan. 37(1998) 853-855.

[21] M. Maki and A. Oyane, TITANIUM JAPAN, the JTS, Tokyo, 65(2017) 48-53.

[22] Home Page of Oyane's Research, URL: https://staff.aist.go.jp/a-oyane/research.html.

[23] Y. Nanbu. TITANIUM JAPAN, the JTS, Tokyo, 65(2017) 106-111.

[24] M. Ueda, C. Fujita and M. Ikeda, Abstract of MRS Fall Meeting, Boston, (2017), URL: https://www.mrs.org/technical-programs/programs_abstracts/bm04_06_02_1

[25] T. Hanawa: Matera Japan, 56(2017), 211-214.

[26] T. Nakano and T. Ishimoto, Material Japan, 4(2019), 181-187.

[27] CNN BUSINESS, URL: https://edition.cnn.com/2013/02/13/tech/innovation/obama-3d-printing/index.html.

[28] I. H. Oh, N. Nomura, and S. Hanada: Mater. Trans., 43(2002), 443-446.

[29] Su-Hua Wu, Yi Li, Yong-Quan Zhang, Xiao-Kang Li, Chao-Fan Yuan, Yu-Lin Hao, Zhi-Yong Zhang and Zheng Guo, Artificial Organs, 37 (2013) E191-E201.

[30] Private Communication of Dr. Y. Matsuda of KAWAMURA GROUP.

[31] Home Page of Fine Company Limited, URL: http://global.fine-revolution.co.jp/titanium-spoons-and-fork/.

[32] Home page of TiG Co., Ltd., URL: http://www.titanium-tig.com/html/wheelchair.html (Japanese Only).

[33] https://www.ottobock.co.jp/prosthetic_le/joint/ (Japanese). 